\title{
Simulation and Evaluation of Building Information Modeling in a real pilot site
}

\author{
María Eguaras ${ }^{\mathrm{a}^{*}}$, Marina Vidaurre $^{\mathrm{b}}$, César Martín-Gómez ${ }^{\mathrm{a}}$, \\ a Building Services and Energy Section, School of Architecture, Universidad de Navarra, \\ Campus Universitario, 31080, Pamplona, Navarra, Spain. \\ ${ }^{\mathrm{b}}$ Construction Section, School of Architecture, Universidad de Navarra, Campus Universitario, \\ 31080, Pamplona, Navarra, Spain. \\ * Corresponding author. Tel.:+34 948425600 ext. 2702. Fax: +34948425629 \\ E-mail address: meguarasm@unav.es
}

\begin{abstract}
:
The current methods of building energy simulation that designers \& engineers (D\&E) use in order to find the energy performance of a building do not take into account the real behavior of the people who will use the building. The main aim of this paper is to show how by merely including the real behavior of people in building simulations there may be differences of up to $30 \%$, through the study of a real pilot site simulation with existing software. These data confirm the possibilities of energy and money saving that energy simulation programs bring about when they include schedules of true use of the building (BIM).
\end{abstract}

Keywords: Architecture, Building Information Model, Energy Efficiency, Human Flow, Simulation, Software.

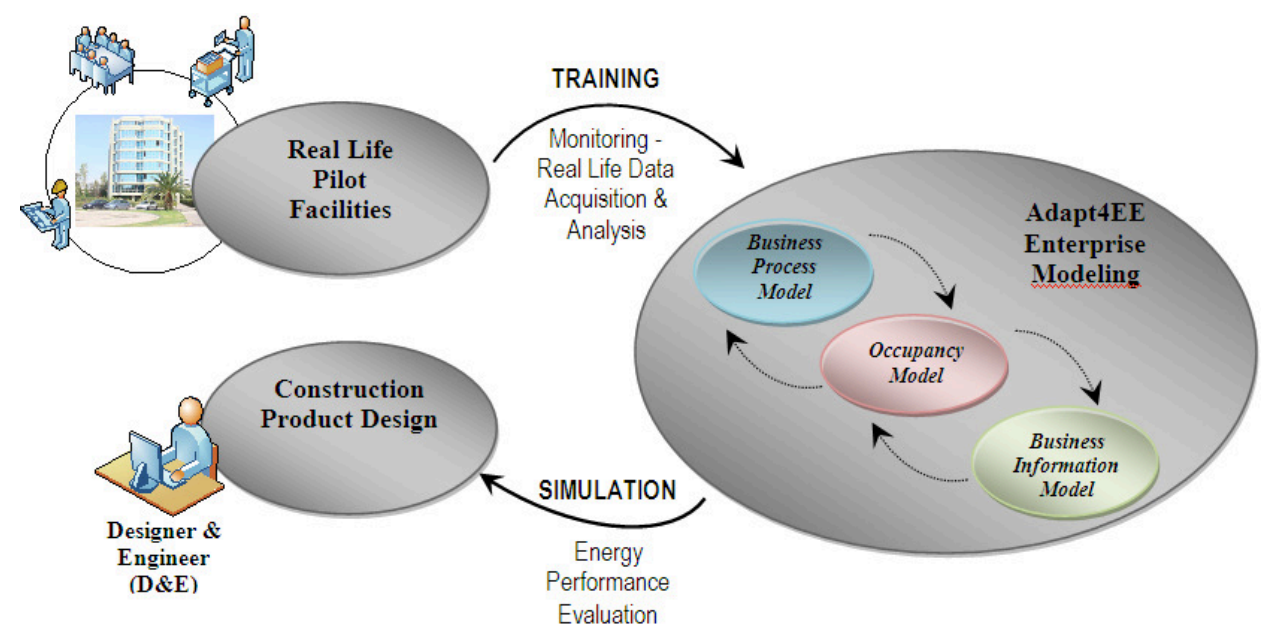

Fig. 1. Graphical abstract (Source: Adapt4EE Project). 


\section{Introduction}

Building simulation is a common practice in the industry. It has undergone a substantial growth both in the academic world and the building industry since its emergence three decades ago. Research in this field of building simulation is also abundant.

Moreover, much research effort within EU funded projects [1] as well as international research action has been devoted to resolving the shortcomings of available building simulations and automation programs and respectivBuilding Information Modeling (BIM) approaches. Recent relevant EU projects such as HESMOS [2] or PEBBLE [3] address these issues and try to make major breakthroughs in Building Information Modeling, though they deal only to certain extend with the occupant factor. They aim at monitoring and modeling occupant responses that are based on individual preferences (comfort of the personnel) under specific environmental conditions [4] [5] [6] [7] [8]. A system for building simulation that produces data about the activity behavior of occupants as members of an enterprise structure and framework can significantly improve the relevance and performance of building simulation tools. This is relevant for engineering spheres, such as building physics, as well as for architects who can analyze and evaluate the performance of a building design [9] [10] [11].

The particular issue presented in this article is a part of a project whose objective is to increase the contemporary architectural frame by incorporating business and occupancy related information, thus providing a holistic approach to the design and evaluation of the energy performance of construction products at an early stage and prior to their completion [12] [13] [14] [15].

The project aims to develop and validate a holistic energy performance evaluation framework that incorporates architectural metadata (BIM), critical business processes (BPM) and consequent occupant behavior patterns, enterprise assets and their respective operations as well as overall environmental conditions.

The project structure, with occupancy behavior (presence and movement) as a central point of reference, will align energy consumption points to all interrelated enterprise aspects (business processes, enterprise assets and utility state and operations).

The project framework and tools will be thoroughly evaluated in terms of modeling, simulation and energy performance with predictive precision, energy gains as well as end-user acceptance, within two different pilot cases, carried out at a hospital and a Multipurpose Office/Commercial Building, more specifically the 'Clínica Universidad de Navarra' in Spain and the 'Estádio Cidade de Coimbra' in Portugal respectively.

In order to execute this study in the framework of the project, one of the pilot sites, the Clínica Universidad de Navarr, has been modelled and analyzed. It is a mixed-use building type that makes it very suitable for this study and allows the extrapolation of the results to a wide range of building types. The Clínica is a large medical center located in Pamplona, in the north of Spain, with recognized prestige in the scientific community. 


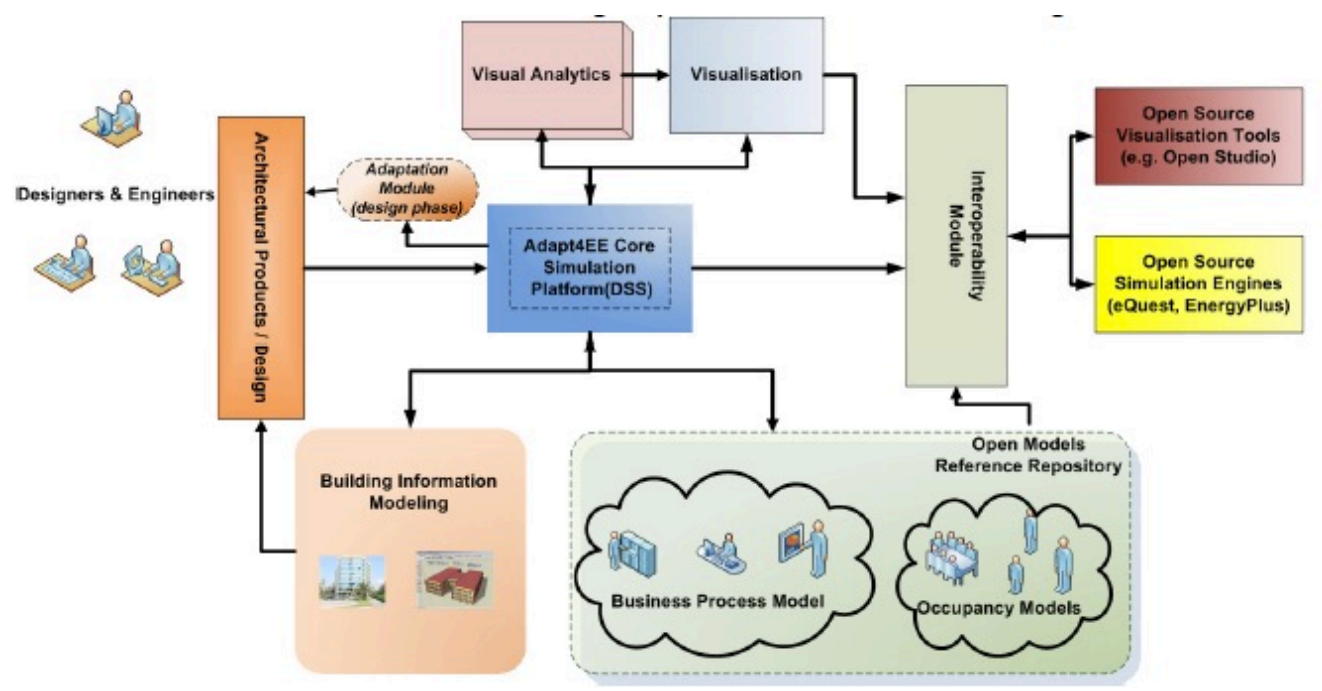

Fig. 3. Project Simulation Platform (Source: Adapt4EE Project).

\section{Methods}

\subsection{General approach}

Architects, designers and engineers (D\&E) need tools that will assist them in creating better and more sustainable construction projects. More specifically, during early design phases the focus on Energy Efficiency should be on designing the most efficient system, taking into consideration the many possible variables (health and comfort performance, building costs, whole life costs, etc) and also including one of the most important factors, that of occupant behavior. However, D\&E lack the tools that will assist them in the complete evaluation of the energy performance of alternative design and making decisions to produce better and more sustainable construction products.

Building simulation has now been established as an integral part of the design process and many simulation tools are available in commercial use and are considered common practice by engineers. Building performance simulation programs must play an important role in the early design process [16] [17] [18] [19] [20].

As far as contemporary research or available technological solutions are concerned, there are no modeling \& simulation tools which take into account the real effect of occupants and respective occupant patterns. The available modeling methods and systems do not deal with activities performed by occupants or with the resulting use of space and movement [5] [21]. The most common form of input in modeling \& simulation systems regarding occupant presence is what are called diversity profiles. These profiles represent the combined behavior of all occupants. A diversity profile describes the presence of occupants and the corresponding energy loads stemming from utility demands. Diversity profiles, however, have failed to propoerly understand 
the dependency of occupancy patterns with overall environmental conditions or temporal variations [22] [23] [24].

Due to the complexity of the problem of understanding user preferences and activities, engineers and existing simulation and design tools, tend to eliminate the influence of active building users as far as possible to optimize building performance, eventually leading to assumptions about average user preferences and behaviors. This not only results in rough and imprecise architectural designs in terms of the energy performance of constructions during future operations, but also in fully automated systems without interaction, poor performance and low end-user acceptance [6].

Uncertainties regarding the behavior of building occupants limit the ability of energy models to accurately predict true building-energy performance during operation. Initial results show that the predicted energy consumption changes by more than $150 \%$ when using all high or all low values for what experts believe reasonably represents occupant behavior [9]. Although numerous sources of modeling inaccurancies and oversimplifications exist, contemporary technological solutions have failed to fully evaluate the sensitivity of energy modeling results due to variability in occupant behavior.

Another shortcoming of building simulation tools is that most programs were originally not intended to be used by building designers. They were designed to be used by research scientists. Usage of these tools generally requires a steep learning curve and as a consequence these tools are mainly used by domain experts [25]. "Simulation tools are neither used to support the generation of design alternatives nor to make informed choices between different design options, and they are neither used for building and/or system optimization" [26].

Occupancy patterns in constructions of commercial use appear to be more complicated, involving multiple individuals, gatherings, single or collective movement patterns and different individual behaviors. Furthermore, in these same cases, occupancy patterns display high correlation with business episodes and their respective daily operations. Moreover, enterprises commonly experience changes in occupancy patterns and ad-hoc requirements due to sudden alterations in business processes as well as personal desertions To this end, the accurate capture and analysis of the data on such trends for applications in enterprise modeling and simulation it extremely useful. Detection of occupant presence has been applied extensively in built environments for applications such as demand-controlled ventilation and security, and occupancy profiles are widely used in building simulations. However, the ability to determine the actual number of occupants in a predefined space, or indeed the patterns of occupant movement, is beyond the scope of current sensing techniques [27].

\subsection{OpenStudio sofware tool}

To perform the Building Information Models of the two pilot cases analysed in this project, the OpenStudio cross-platform (Windows, Mac, and Linux) software tool has 
been used. This collection of tools supports whole building energy modeling using EnergyPlus [28].

One of the strengths of OpenStudio is that it is a free tool which is part of an open source project to facilitate community development, extension, and private sector adoption. The OpenStudio graphical applications include the SketchUp Plug-in [29], the stand alone OpenStudio application, and ResultsViewer. It is a graphic energy modeling tool and includes visualization and editing of schedules, editing of loads, constructions and materials, a drag and drop interface to apply resources to spaces and zones, a visual HVAC and service water heating design tool, and high level results visualization [30]. OpenStudio also gives the modeler integrated access to data from the Building Component Library. ResultsViewer enables browsing, plotting, and comparing EnergyPlus output time series data. It allows building researchers and software developers to quickly get started through its multiple entry points, including access through $\mathrm{C}++$, Ruby, and $\mathrm{C \# .}$

\subsection{Pilot Site: Clínica Universidad de Navarra}

The pilot site analyzed in this study is the Clínica Universidad de Navarra which is a medical center and hospital with a high degree of medical specialization, constant technological innovation and good teamwork.

It has been selected because: it is a commercial building with mutifaceted areas and operations, consisting of sub-areas with well-defined daily business operations which are highly correlated to specific "business" services, respective business episodes and occupancy patterns. It also belongs to commercial areas of great importance and difficulty for the D\&E Industry. In this case, real enterprise data will be acquired, monitored and analyzed concerning the actual space utilization and business scenarios in order to train and calibrate the project simulation models accordingly.

The Clínica was created in 1961 and is part of the University of Navarra, a private nonprofit institution guided by Christian principles.Therefore, the research, teaching and support are carried out together with the Faculties of Medicine, Science, Pharmacy and Nursing and the Center for Applied Medical Research (CIMA).

In 2010 , the Clínica carried out a total of 136,667 patient consultations and formalized 13,828 hospital admissions, with an average stay of 6.1 days. It also attended 9,616 emergencies, carried out 12,375 surgical operations, and recorded 84,767 hospital stays, with the same average stay of 6.1 days.

The Clínica Universidad de Navarra employs over 2,300 professional staff. It has 400 beds with 16 operating theatres and 2 delivery rooms. It also has 12 adult ICU beds, 6 paediatric ICU beds and 12 for special hospitalization. For out-patients it has 254 consultation rooms and 154 examination rooms, all in $75.000 \mathrm{~m} 2$ of constructed space.

Since this is a complex building, several areas have been selected to model instead of the whole building, while trying to reflect the mixed uses of uses of the building.

The eighth floor is proposed as a Pilot Area because the different activities involved in the whole hospital use this floor of the building and could be studied as a scale laboratory in order to reflect the mixed uses of the building: medical bays, medical 
offices, administration offices, meeting rooms, hospitalization areas, consultation areas and restrooms around a long corridor with open spaces used as a waiting area. The selected areas of the floor studied in this project is approximately 3,500 square meters and has over 150 occupants.

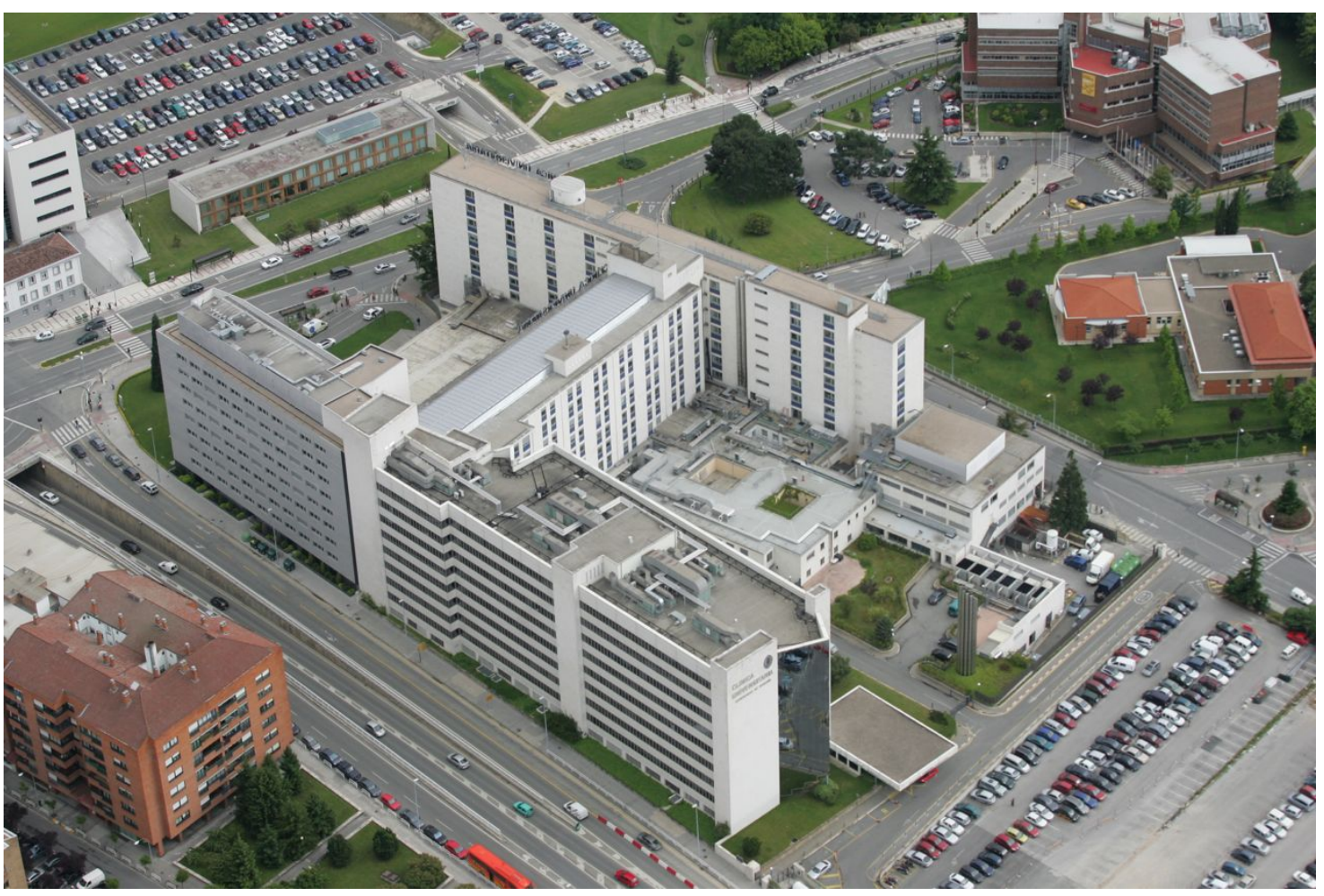

Fig. 4. External view of the Clinica Universidad de Navarra (Source: CUN).

As a result, for the eighth floor, four basic models have been made using default OpenStudio templates: doctors and MIR offices; two MIR meeting rooms; the day-care center, the dialysis area and finally the consultation area.

On the ground floor, we have chosen the whole area dedicated to coordinating hospital admission (check-in, check-out and payment), near the west public entrance. There is a main open space with some offices boxes without walls. The area is around 865 square meters with approximately 125 occupants.

During the preparation phase of the model, all the information was gathered thanks to the architect in charge of the design of the selected area (construction materials, surfaces, areas...). Moreover, many Clínica staff were interviewed. The loads (people, lights, equipment) and the schedules gathered have been translated to OpenStudio templates. 


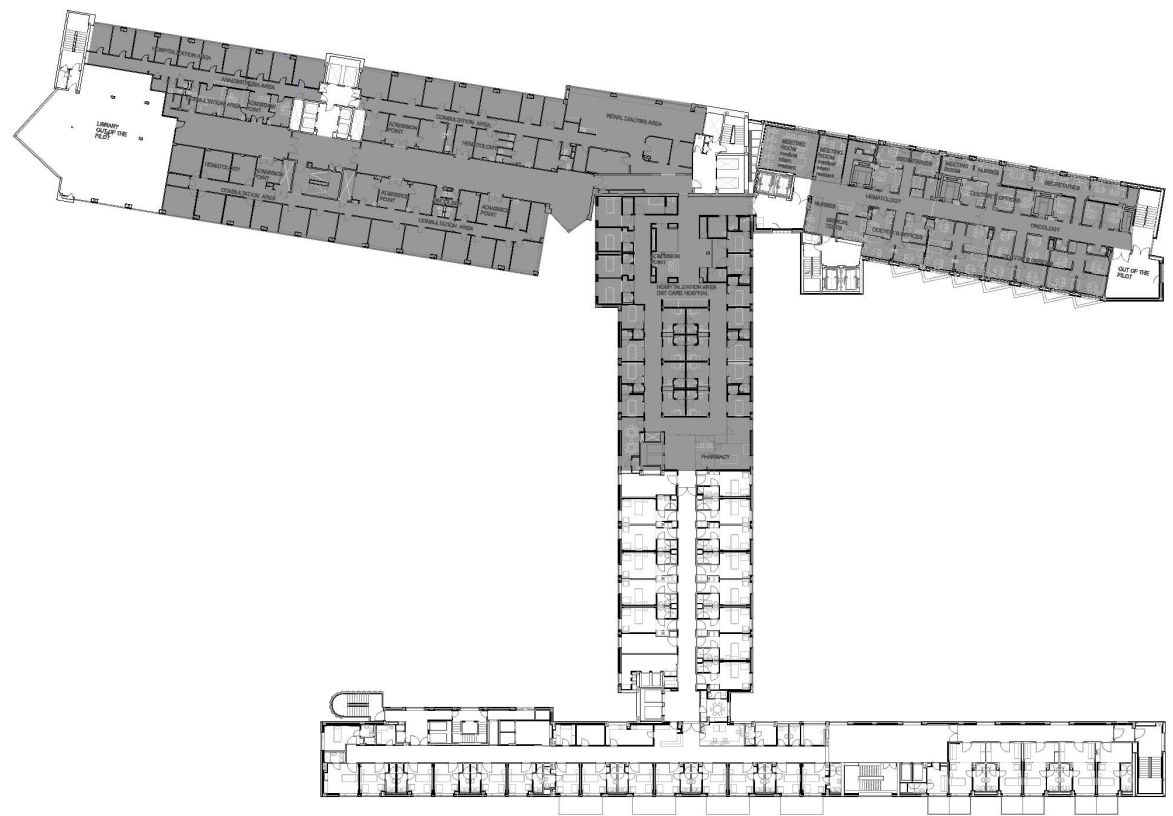

Fig. 5. Eighth floor with the modelled areas selected.

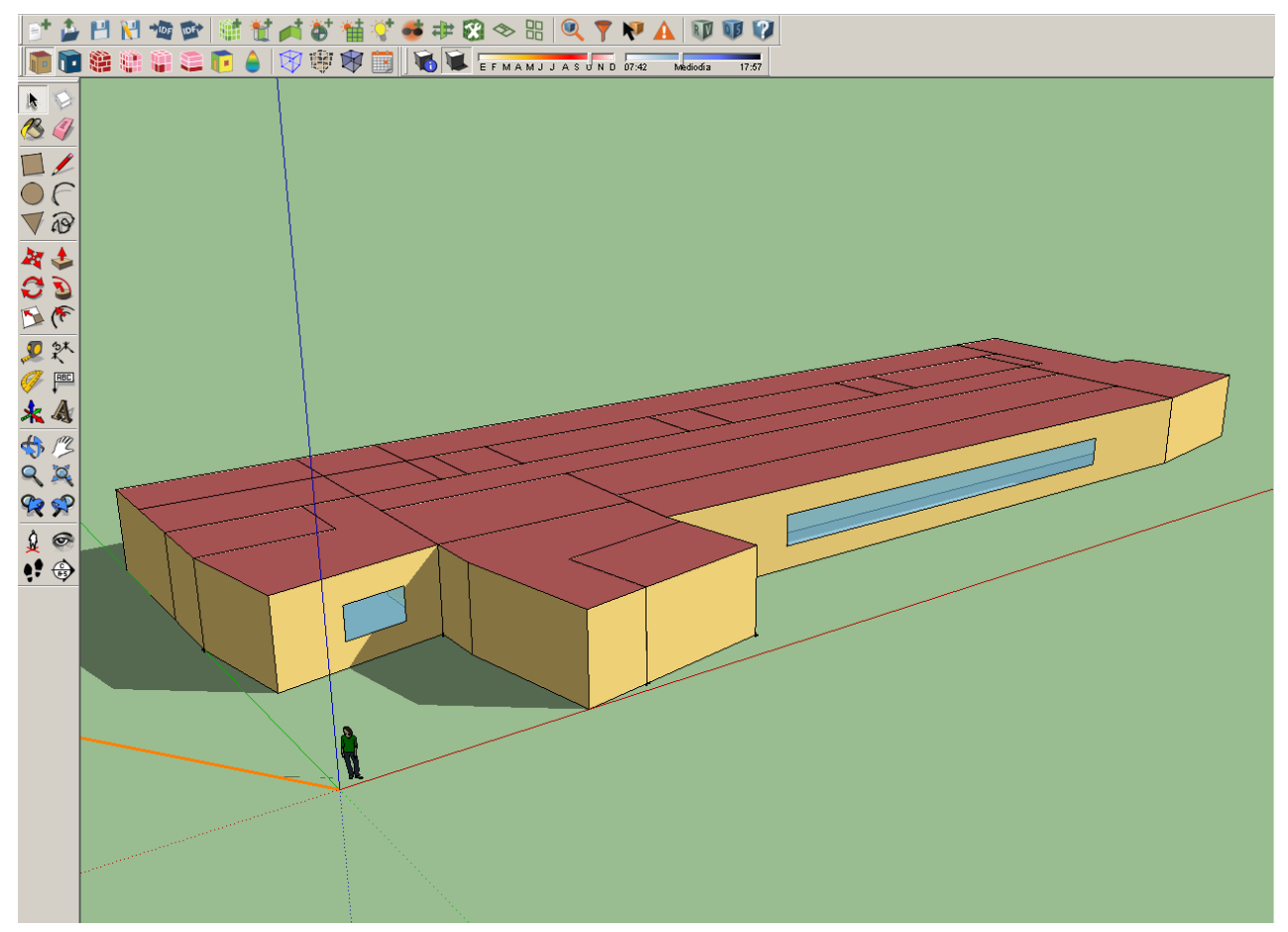

Fig. 6. OpenStudio image that represents the Doctors and MIR offices in the right side of the eighth floor. 


\section{Building Simulation Results}

Modeling buildings as complex as those presented in this study present several problems which only an expert in this type of software is capable of solving. A brief description of the steps taken in order to solve this type of errors will be presented.

The first step is to simplify the geometry of the building as much as possible, so the designers \& engineers (D\&E) have to clean the CAD plans in order to import it to OpenStudio software. The CAD file contains many lines which may be confusing; a schematic drawing with the basic shape of the building and the spaces is enough.

Similarly, complex forms or connections between spaces may to be avoided in order to clarify the spaces. In the same way, if the number of zones and spaces is high, some errors may occur, for example, the sudden crash of the program, or some surfaces change their position when modifying their characteristics.

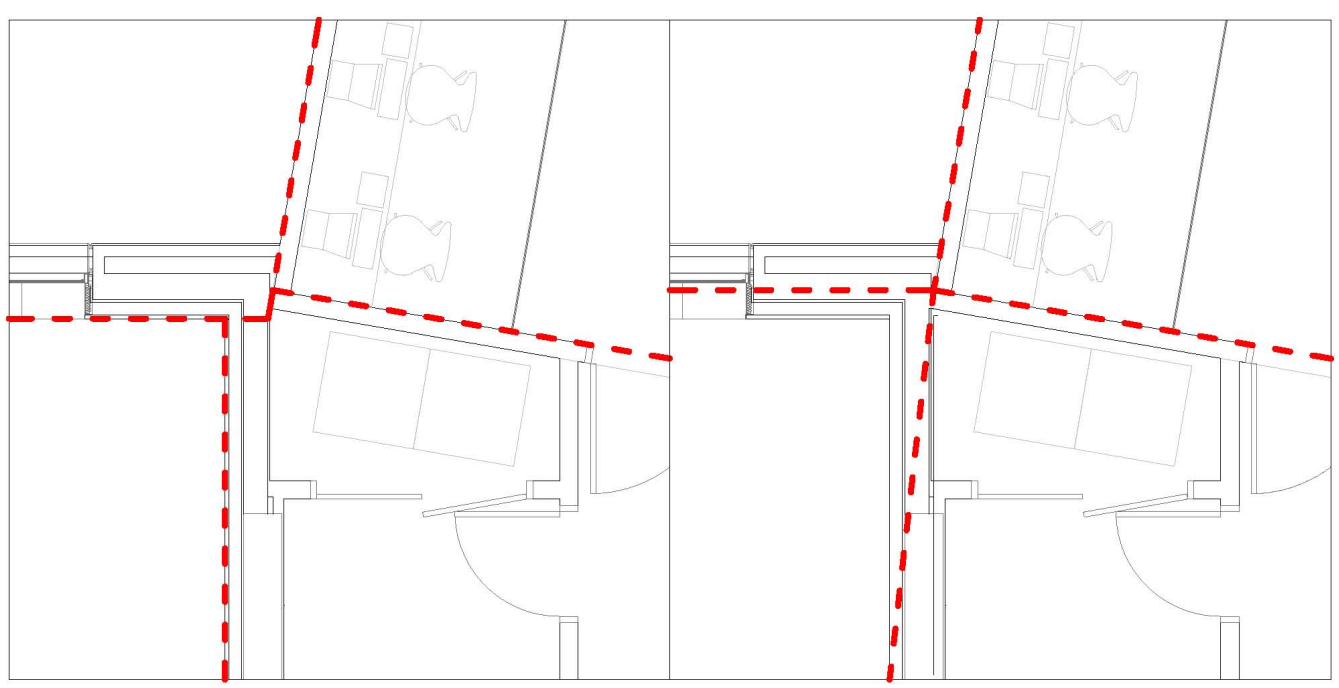

Fig. 10. Picture of the simplifications that D\&E have to made in order to import the CAD file.

Due to these problems the designer should save the file every time that a change in the geometry or properties is made to avoid a future error; if not the program may unexpectedly cut out and all the progress made in the model will be lost.

Another drawback that should be addressed is the fact that it is not possible to select a group of surfaces to assign a set of characteristics to the whole group. You are forced to assign them one by one, which is extremely tedious if the model is complex.

\subsection{Comparing Open Studio templates with actual data}

The templates in OpenStudio are designed for specific building types and are loaded with construction, schedule, and internal load data for various time-periods and for all U.S. climate zones [31]. 
In version 0.10 .0 .10520 there are 17 templates available. These templates can be customized to meet the designer needs.

Of all the templates mentioned above, two templates are used in the CUN pilot site: the Hospital and Outpatient templates. Only schedules and internal load data for the template were used in order to model the pilot selected area. The construction materials and the characteristics of the surfaces were changed to be similar to those already in place in the Clínica.

The model of the two MIR meeting-working rooms was made by first using the Hospital template and secondly with the Outpatient one, in order to compare the differences between these two templates provided by OpenStudio.

Then a more real simulation has been made with the data gathered in the Clínica using the Business Process Models (BPM) made within the EU project, and the actual data of loads (people, schedules, type of lights, number and type of equipment).

The following table shows the loads considered in both templates and in the model with actual data.

The next figures represent the schedules that are assigned to the loads (occupation, lights and electric equipment) in the templates as well as in the new model.

After this first approach to a more realistic model, the results regarding energy consumption, and the addition of heat energy due to the loads, have been gathered and are shown in figures 13,14 and 15 , and tables 3,4 and 5.

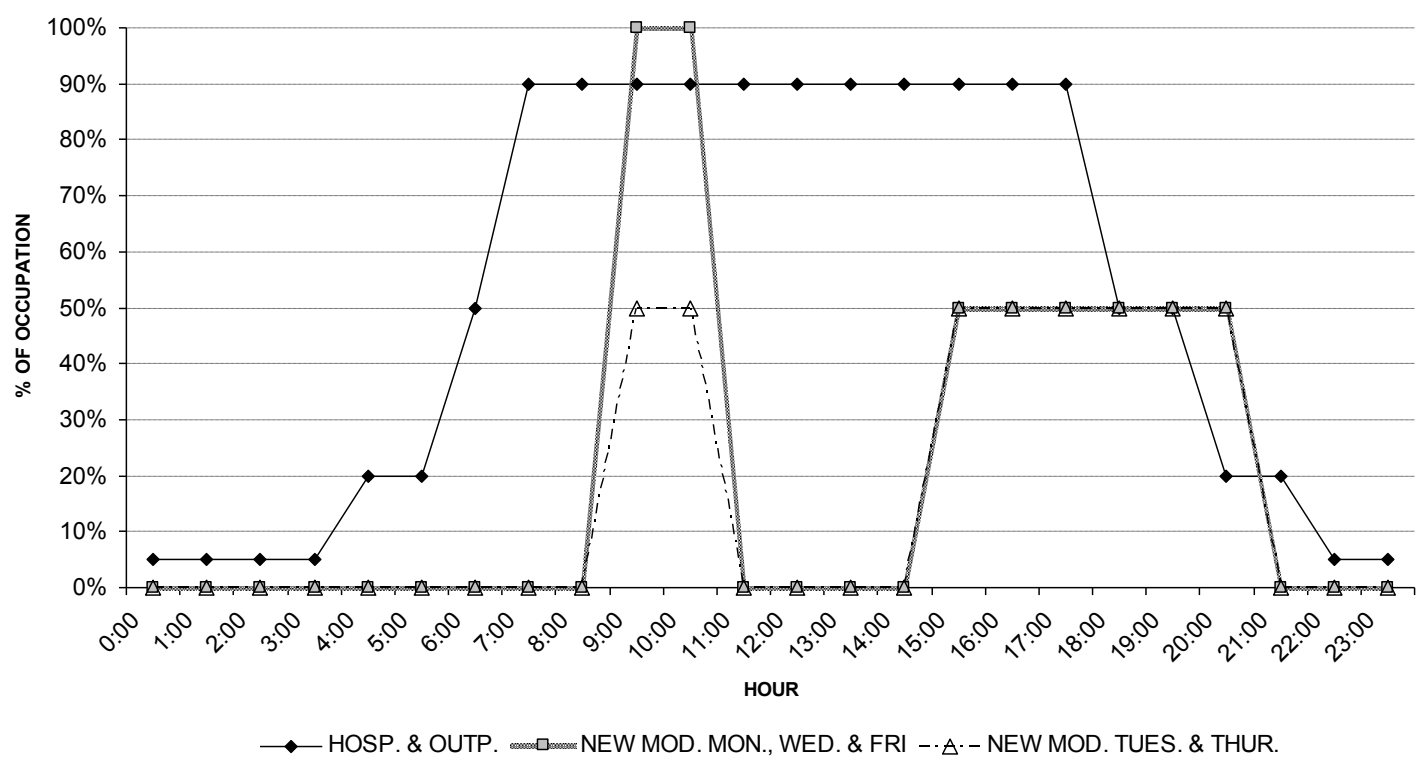

Fig 11. Occupation schedules from Monday to Friday 


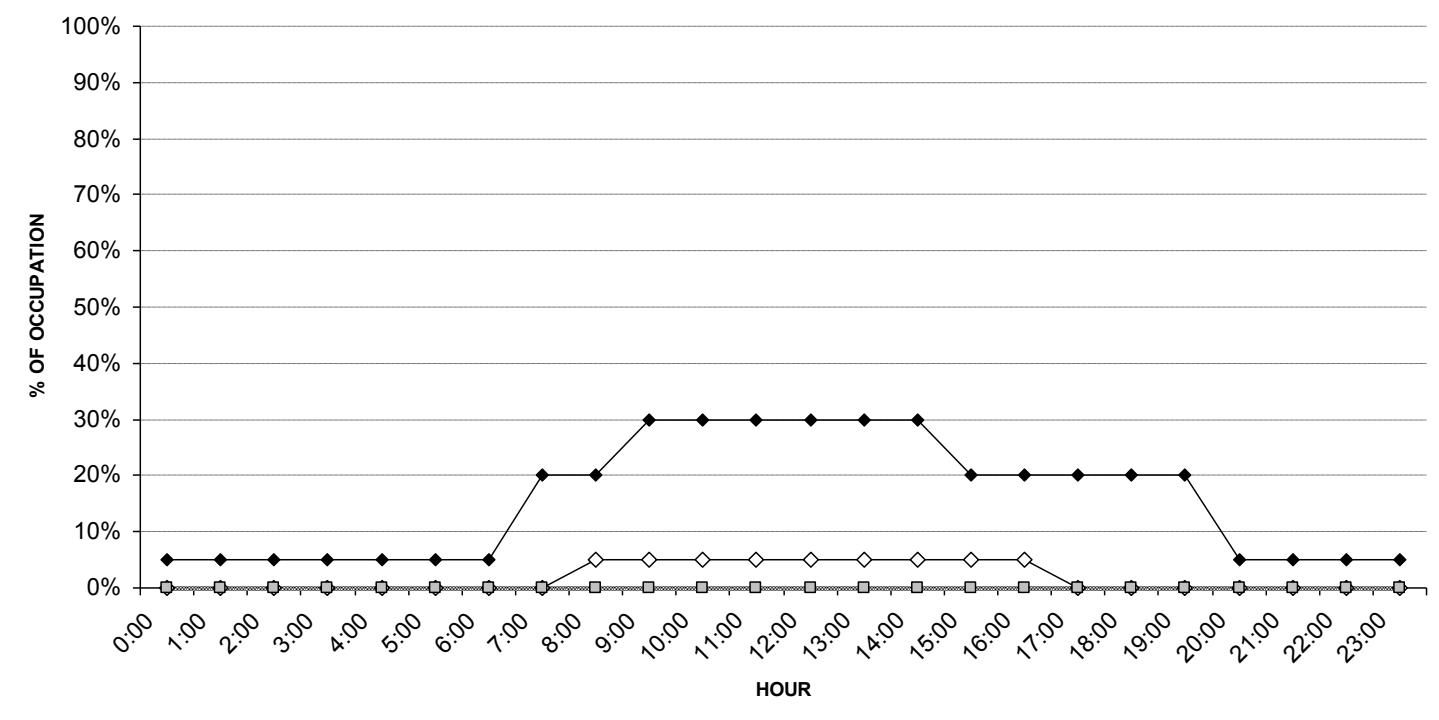

$\multimap$ HOSP. \& OUTP. SAT. $\prec-$ HOSP. \& OUTP. SUN. $\square-$ NEW MOD. SAT. \& SUN. (0\%)

Fig. 12. Occupation schedules Saturday and Sunday

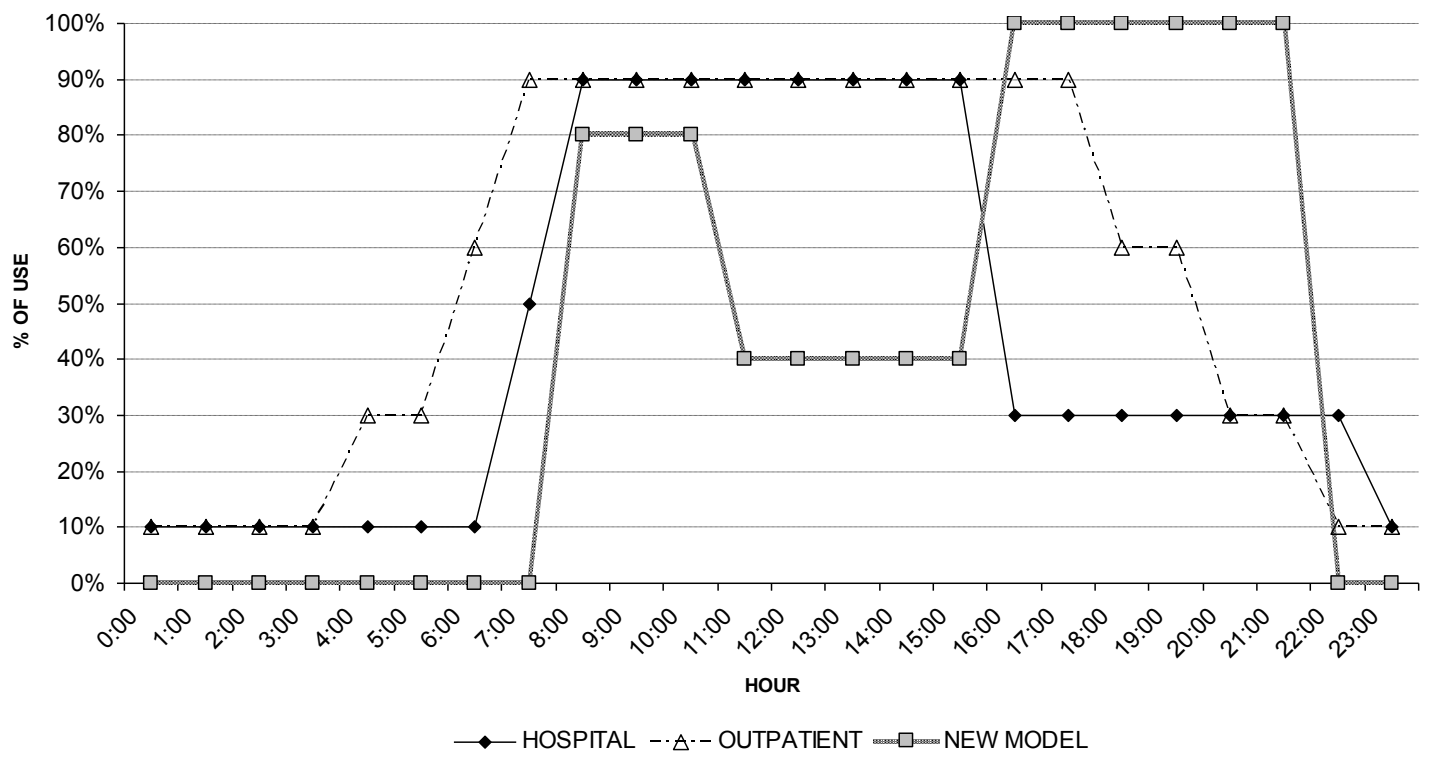

Fig. 13. Lights schedules from Monday to Friday 


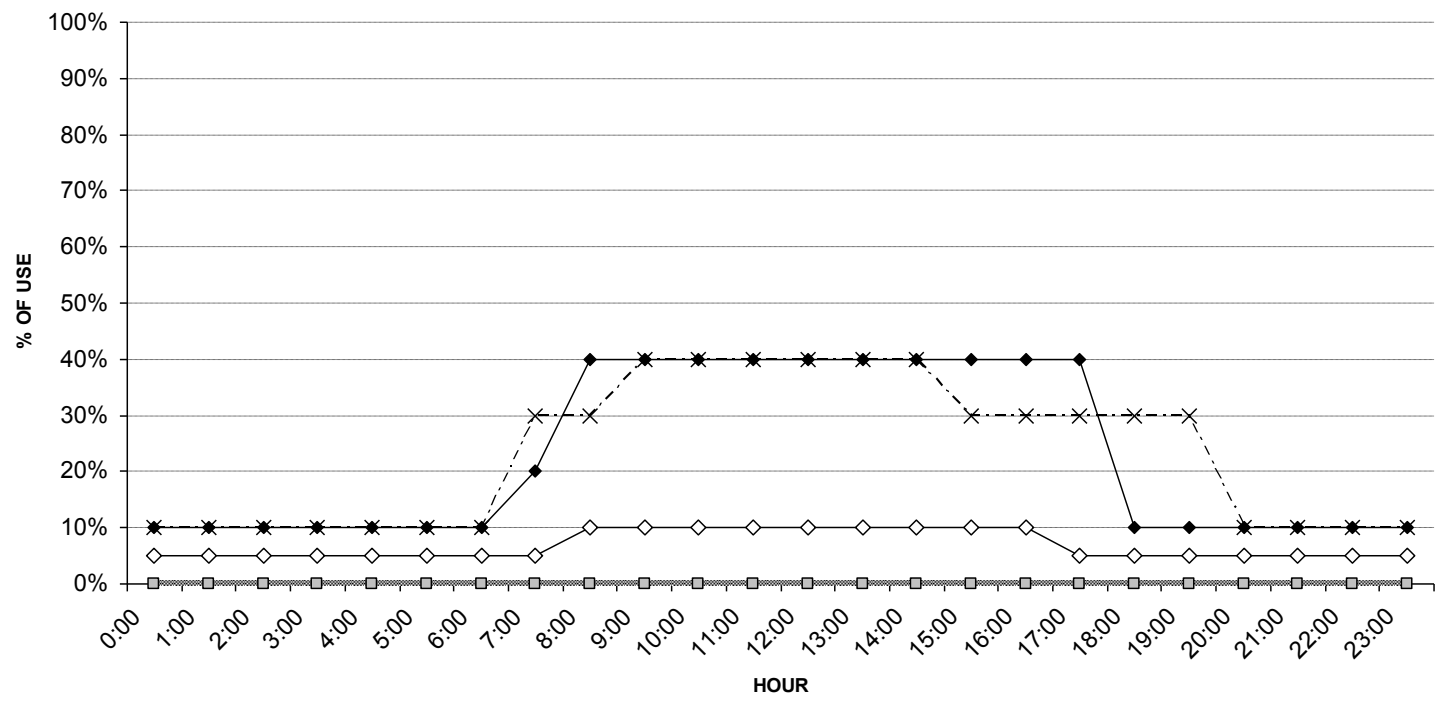

$\multimap$ HOSP. SAT. $-\cdot * \cdot-$ OUTP. SAT $\prec$ HOSP. \& OUTP. SUN. $=\square-$ NEW MOD. SAT \& SUN $(0 \%)$

Fig. 14. Lights schedules Saturday and Sunday

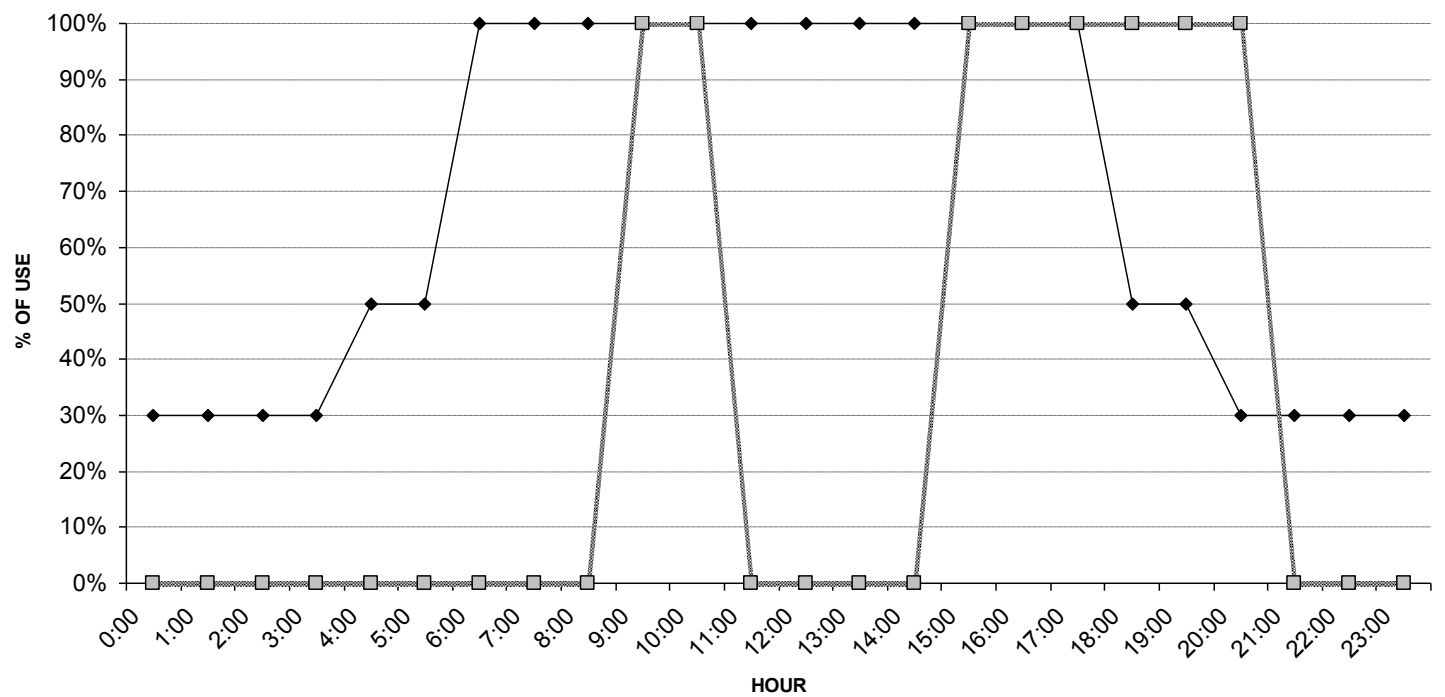

$\longrightarrow$ HOSP. \& OUTP. $-\square-$ NEW MODEL

Fig. 15. Electric equipment schedules from Monday to Friday 


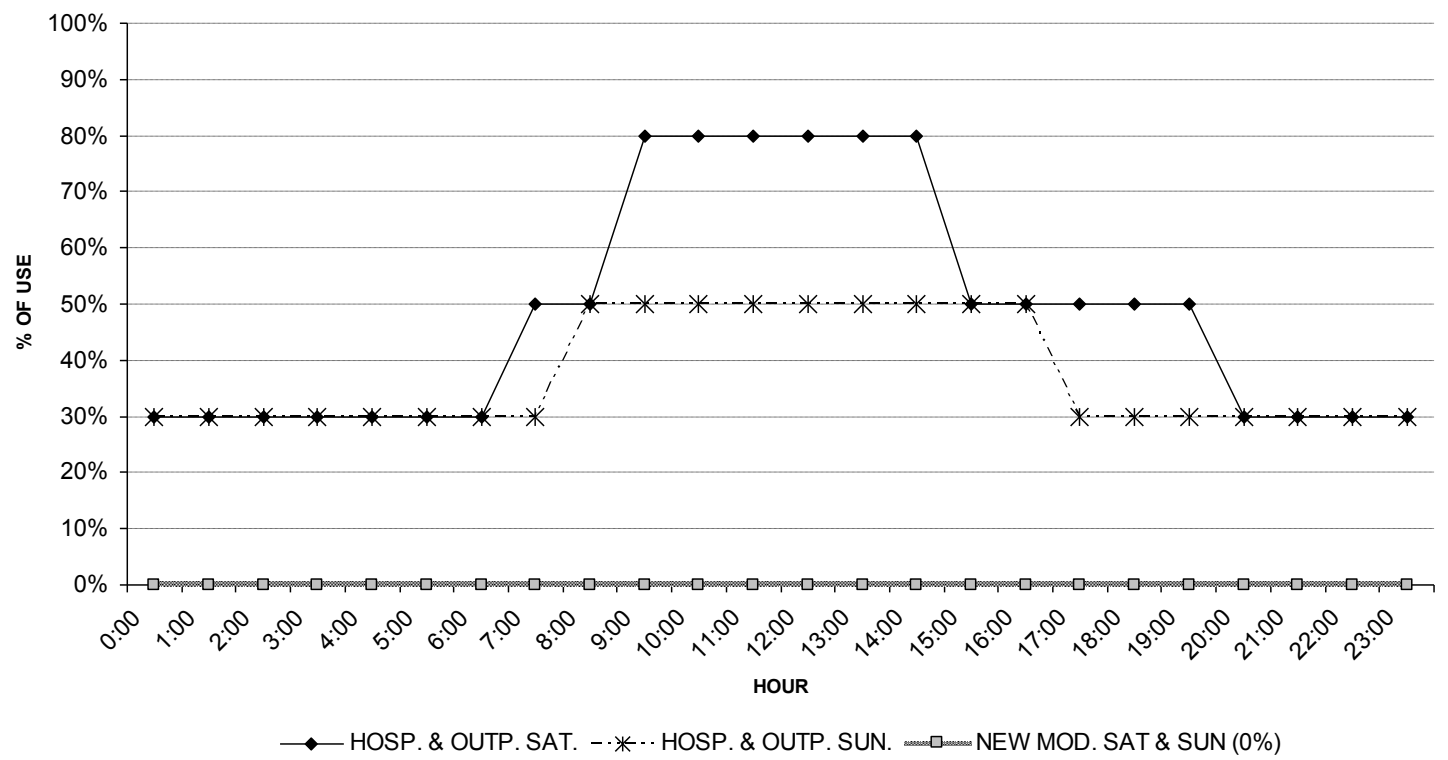

Fig. 16. Electric equipment schedules Saturday and Sunday

After this first approach to a more realistic model we have the results regarding energy consumption, and the addition of heat energy due to the loads exposed in figures 17 , 18 and 19 , and the tables 3,4 and 5.

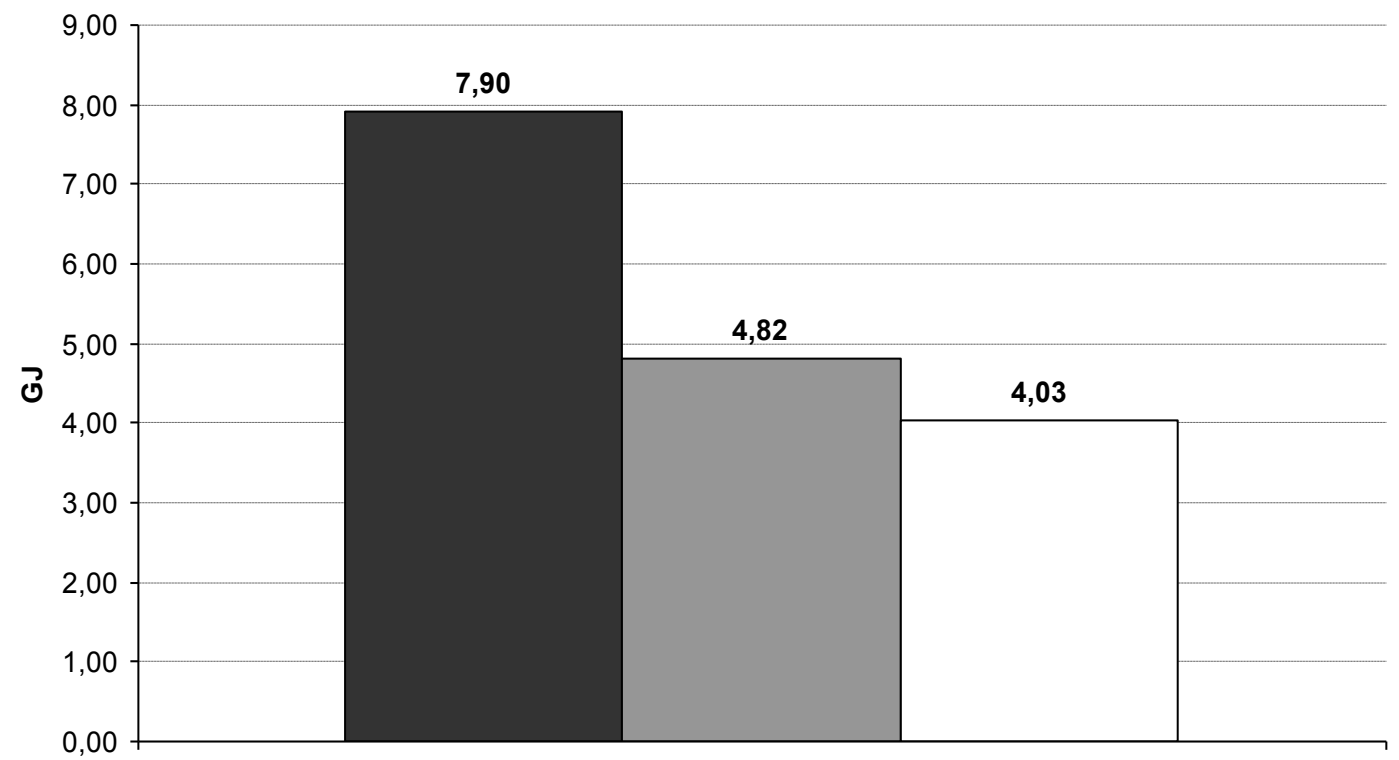

HEATING LOADS ANNUAL SUM

口 NEW MODEL $\square$ HOSP. TEMPL. $\square$ OUTP. TEMPL.

Fig. 17. Energy for heating in each of the simulations 


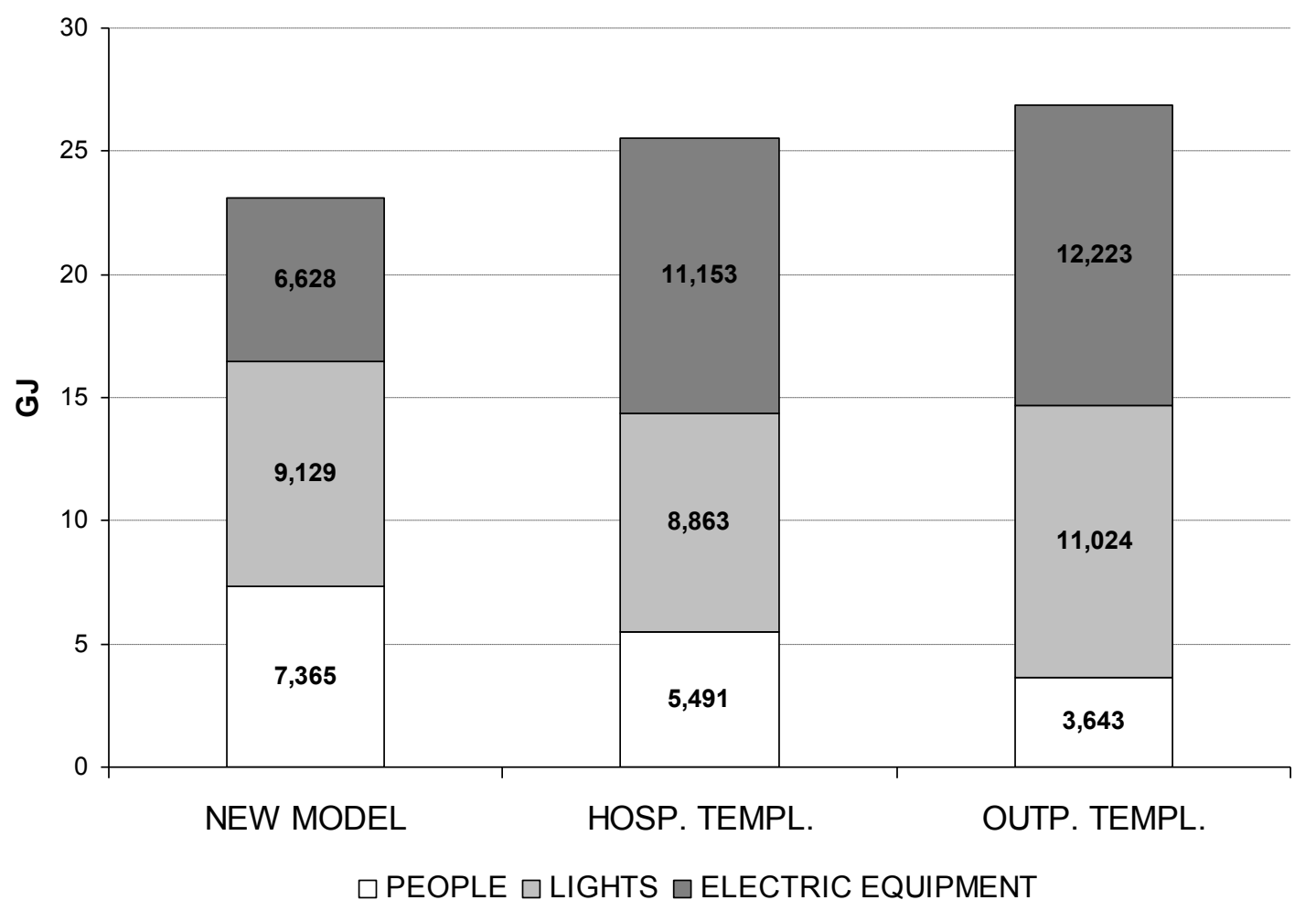

Fig. 19. Annual sensible heat addition due to the loads in each simulation

As shown in the figures above, the differences between the default templates provided by OpenStudio and the new real template created with actual data, are of up to thirty $\%$ higher for the heating and cooling needs.

\section{Discussion}

Despite the effort to make real schedules and loads in order to create a new OpenStudio profile, this study is part of an ongoing project, so no tangible results have been reached until the definitive and real monitoring of the pilot site is carried out. In the absence of definitive monitoring data, there are a lot of uncertainities, so this study gives rise to a discussion of the real importance of using occupancy patterns in building energy simulation during the early design phases [32] [33] [34] [35] [36] [37].

The main unknown data before real data is gathered are occupant behavior, actual weather and infiltrations [38], which is why many assumptions have been made to design the schedules for lights and equipment. We cannot know whether the users switch off lights or computers when they all leave the rooms in the morning. For the same reason, the average values recommended by ASHRAE 2009 have been used to consider energy consumption of computers and monitors [22] [39] [40].

The differences shown underline the need to make a prior accurate study of the real human occupancy of the building, that is to say, information must be included in the 
early design phases Business Process Models in order to simulate the energy efficiency as faithfully as possible, since, as we have seen, the templates that BIM software tools provide are not as precise as the energy performance needs. In conclusion, the D\&E has to gather more data on the different areas and design schedules and loads closer to real use of the building [41].

In the same way, a prior study of the equipment, lights and schedules of use has to be made to complete this simulation as realistically as possible, to include in the model real HVAC systems behavior.

One of the main conclusions of this study is that it is possible to save a great amount of energy by merely taking into account the occupancy patterns without architectural changes, that is, with minimal financial investments [42] [43] [44] [45].

Energy-intelligent constructions incorporating innovative Information and Communications Technology (ICT) will be able to efficiently adapt to occupant needs and preferences, and maximize energy performance, while at the same time comply with overall business requirements [46] [47]. This will be achieved through the fusion of two (currently separate) worlds: Building Information Modeling (BIM) and Business Process Modeling (BPM), with the occupants as the main catalyst. This fusion, among other obvious advantages, will also allow for enhanced diagnosis and renovation of existing constructions, and will generate infrastructures and simulation environments to assess vartiants of the environmental performance of buildings, tools for dynamic building evaluation during run-time, and assist in optimisation based on multidimensional/multi-criteria constraints.

Once the project comes to fruition and the results have been contrasted, it will allow energy savings with minor investment, so this study presents potential energy savings in mixed-used buildings. In addition, it will allow the application of such results and software in other areas of knowledge such as, for example, fire safety [48].

\section{Acknowledgements}

This research has been done for the 'Occupant Aware, Intelligent and Adaptative Enterprises', Adapt4EE project, co-funded by the European Commission within the $7^{\text {th }}$ Framework Programme (FP7/2007-2013) under Grant Agreement n 288150.

Esperanza Lozano Guerra, CUN Assistant Manager.

\section{References}

[1] http://ec.europa.eu/information_society/activities/sustainable_growth/funding/prj_buidings/index_en.htm

[2] http://cordis.europa.eu/fetch?CALLER=PROJ_ICT_TEMP\&ACTION=D\&CAT=PROJ\&RCN=95500

[3] http://www.pebble-fp7.eu/ 
[4] Chang W, Hong T. Statistical Analysis and Modeling of Occupancy Patterns in Open-Plan Offices using Measured Lighting-Switch Data. Ernest Orlando Lawrence Berkeley National Laboratory, January 2013.

[5] Zimmermann G. Modeling the building as a system, 8th International IBPSA Conference. 2003 p. 1483 - 1490.

[6] Zimmermann G. Modeling and simulation of dynamic user behavior in buildings - a lighting control case study", eWork and eBusiness in architecture, engineering and construction: Proceedings of the 6th European conference on product and process modeling. 2006, p. 309-316, Taylor \& Francis Group.

[7] Corgnati S.P, Fabrizio E, Filippi M. The impact of indoor thermal conditions, system controls and building types on the building energy demand. Energy and Buildings 2008; 40(4):627-636.

[8] Kravanja Z, Cucek, L. Multi-objective optimisation for generating sustainable solutions considering total effects on the environment. Applied Energy 2013; 101:67-80.

[9] Clevenger C, Haymaker J. The Impact of the Building Occupant on Energy Modeling Simulations, Joint International Conference on Computing and Decision Making in Civil and Building Engineering, 2006, Montreal, Canada.

[10] Crawley D, Lawrie B, Winkelmann L.K, Buhl F.C, Huang W.F, Pedersen Y.J, Strand C.O, Liesen R.K, Fisher R.J, Witte D.E, Glazer M.J and J. EnergyPlus: creating a new-generation building energy simulation program. Energy and buildings 2001. 33 (4):319-331.

[11] Crawley D.B, Hand J.W, Kummert M, Griffith B.T. Contrasting the capabilities of building energy performance simulation programs. Building and Environment 2008; 43(4):661-73.

[12] http://www.adapt4ee.eu/adapt4ee/

[13] Hensen J.L.M. Towards more effective use of building performance simulation in design. Developments in Design \& Decision Support Systems in Architecture and Urban Planning, 2004:291-306. Eindhoven, the Netherlands.

[14] Malavazos C, loannidis D, Kehagias D, Tzovaras D. Energy and behavioral modeling and simulation for EEbuilding design.

[15] Ioannidis D, Tzovaras D, Malavazos C. Occupancy and Business Modeling. 9th European conference on product and process modeling (ECPPM 2012), 3rd Workshop on eeBDM, eeBIM, Reykjavik, Iceland, July 2012.

[16] Soebarto V.I, Williamsoon T.J. Multi-criteria assessment of building performance: theory and implementation. Building and environment 2002; 36:681-690.

[17] Augenbroe G. Building simulation trends going into the new millennium. Proceedings of the seventh international IBPSA conference. 2001:15-27.

[18] Hong T, Chou S.K, Bong T.Y. Building simulation: an overview of developments and information sources. Building environment 2000; 35(4):347-361.

[19] Struck C, Kotek P, Hensen J. On incorporating uncertainty analysis in abstract building performance simulation tools. Proceedings of the $12^{\text {th }}$ symposium for building physics. 2007:193-205.

[20] Petersen S, Svendsen S. Method for simulating predictive control of building systems operation in the early stages of building design. Applied Energy 2011; 88:4597-4606.

[21] Robinson R. Some trends and research needs in energy and comfort prediction. Proceedings of comfort and energy use in building. 2006. Windsor, UK.

[22] Abushakra B, Sreshthaputra A, Haberl A, Claridge J and D. Compilation of diversity factors and schedules for energy and cooling load calculations, ASHRAE research project 1093-rp, 2001. Texas, USA.

[23] Burgeois D. Detailed occupancy prediction, occupancy-sensing control and advanced behavioral modeling within whole-building energy simulation. 2005. Université Laval, Quebec, Canada.

[24] Page J. Simulating occupant presence and behavior in buildings. 2007. École polytechnique fédérale de Lausanne, Switzerland. 
[25] Papamichael K, LaPorta J, Chauvet $\mathrm{H}$. Building design advisor: automated integration of multiple simulation tools. Automation in construction 1997, 6(4):341-352.

[26] Hopfe C.J, Hensen J. An approach to use building performance simulation to support design optimization. Proceedings of the forum bauinformatik, 2006.

[27] Dong B, Andrews B, Lam K.P, Hoynck M, Zhang R, Chiou Y-S, Benitez D. An information technology enabled sustainability test-bed (ITEST) for occupancy detection through an environmental sensing network. Energy and Buildings 2010, 42(7):1038-1046.

[28] Whole building energy simulation program that engineers, architects, and researchers use to model energy and water use in buildings.

[29] The Plug-in allows users to quickly create geometry and assign space attributes using the built-in functionality of SketchUp including existing drawing tools, integration with Google Earth, Building Maker, and Photo Match.

[30] Radiance can also be integrated into the simulation workflow. This is accomplished by using an annual Radiance simulation to measure daylighting, and then creating an electric lighting usage schedule for EnergyPlus.

[31] http://openstudio.nrel.gov/

[32] Dong B, Andrews B. Sensor based occupancy behavioral pattern recognition for energy and comfort management in intelligent buildings, 11th International Building Performance Simulation Association IBPSA Conference, 2009.

[33] Lam K.P, Höynck M, Zhang R, Andrews B, Chiou Y.S, Dong B, Benitez D. Information-theoretic environmental features selection for occupancy detection in open offices. Proceedings of Building Simulation 2009, Glasgow.

[34] Hutchings J, Ihler A, Smyth P. Modeling count data from multiple sensors: a building occupancy model, IEEE International Workshop on Computational Advances in MultiSensor Adaptive Processing, December 2007.

[35] Mahdavi A, Pröglhöf C. Toward empirically based models of people's presence and actions in buildings, Proceedings of Building Simulation, Scotland 9:537-544.

[36] Wang D, Federspiel C.C, Rubinstein F. Modeling occupancy in single person offices. Energy and buildings 2005; 37(2):121-126.

[37] Fritsch R, Kohler A, Nygard-Ferguson M, Scartezzini J.L. A stochastic model of user behavior regarding ventilation. Building and Environment 1990; 25(2):173-181.

[38] Jahn M, Eisenhauer M, Serban R, Salden A, Stam A. Towards a Context Control Model for Simulation and Optimization of Energy Performance in Buildings. 9th European conference on product and process modeling (ECPPM 2012), 3rd Workshop on eeBDM, eeBIM, Reykjavik, Iceland, July 2012.

[39] Packham N, McNulty N, Vanderstockt Y, Byrne M. Intelligent Control of Energy - A Reality for Building Management Systems. Intelligent computing in Engineering- ICE08, 2008.

[40] Klemes J.J, Kravanja Z, Varbanov P, Lam HL. Advanced multimedia-engineering education in energy, process integration and optimisation. Applied Energy 2013; 101:33-40.

[41] Chung W. Review of building energy-use performance benchmarking methodologies. Applied Energy 2011; 88:1470-1479.

[42] Kissock J, Ege C. Measuring industrial energy savings. Applied Energy 2008; 85:347-361.

[43] Martin P, O'Callaghan P, Probert D. Environmental Auditing: Estimating and Reducing Corporate Greenhouse-Gas Emissions using Monitoring and Targeting Software Systems. Applied Energy 1992; 42:269-288.

[44] Hong T, Koo Ch. Kwak T. Framework for the implementation of a new renewable energy system in an educational facility. Applied Energy 2013; 103:539-551.

[45] Duic N, Guzovic Z, Kafarov V, Klemes J.J, Mathiessen B, Yan J. Sustainable development of energy, water and environment systems. Applied Energy 2013; 101:3-5. 
[46] Marinakis $\mathrm{V}$, Doukas, $\mathrm{H}$, Karakosta $\mathrm{Ch}$, Psarras $\mathrm{J}$. An integrated system for buildings 'energy-efficient automation: Application in the tertiary sector. Applied Energy 2013; 101:6-14.

[47] Connolly D, Lund H, Mathiesen B.V, Leahy M. A review of computer tools for analysing the integration of renewable energy into various energy systems. Applied Energy 2010; 87:1059-182.

[48] Woodrow M, Bisby L, Torero J. A nascent educational framework for fire safety engineering. Fire Safety Journal 2013; 58:180-194.

"Simulation and evaluation of Building Information Modeling in a real pilot site"

María Eguaras Martínez, Marina Vidaurre Arbizu, César Martín-Gómez

Applied Energy 114 (2014) 475-484

ISSN 0306-2619

DOI: 10.1016/j.apenergy.2013.09.047 